\title{
The Language Factor in Nigeria's National Development: a Development Communication Perspective
}

\author{
Muyiwa Popoola \\ Department of Communication and Media Studies Ajayi Crowther University, Oyo Oyo State, Nigeria
}

\begin{abstract}
This paper discusses the need to adopt a national language in Nigeria as a factor for enhancing national development. It argues that the multiplicity of languages in Nigeria presents immense difficulties in using communication to help bring about positive change in all spheres of the country's national life. Since language is inextricably tied to a people's culture, for any language of communication to be used meaningfully for Nigeria's national development, it must be accepted and understood by a majority of the citizens. The paper bases its suggestions for the management of this volatile issue on the diffusion of innovation paradigm and the language experiments of some developed countries of the world. It concludes that the multiplicity of languages in Nigeria has been a disincentive for the country's development. The paper offers a number of options that can be considered in adopting a national language for the country. Consequently, the paper posits that the English language should continue to be the language for communication and business in Nigeria, for the fact that it has the greatest geographical spread around the globe than any language, and also because technological inventions in the area of mass communication are a great obstacle to adopting any of the nation's indigenous languages. There is no substitute to the use of English language as a medium of development communication in Nigeria.
\end{abstract}

Keyword: Language, Communication, Development

\section{Introduction}

The treatment of the development message is a critical factor in the success of any development programme. At the passing of the era of what became known as the dominant paradigm of development (1960s and early 1970s), a new approach to development communication emerged. As summarized by Nwuneli (1993, p. 26), the new approach advocated the popularization of the development and design of campaign messages by making culturally sensitive, language specific and in tune with the social realities of the people of the developing world. Therefore, central to the issue being addressed in this paper is the proposition that the language in which a development message is disseminated is a critical aspect of the message treatment. Along this trajectory, Nwuneli (1986, p. 203) argued that the indigenous language of a community is the best suited for the purpose of conveying any message to that community.

The human community is distinguished by the sophistication of its mode of communication. Essentially, communication is the sharing of meaning through signs and symbols. According to Berger (1987, p. 19), language is a system of symbols and it is the basic tool of communication Language is, therefore, a system of symbols that may be oral or written, used in a fairly standardized way by members of the same community to ascribe meaning. Thus, every human community has a language through which its members communicate and they communicate better with one another because this language is indigenous to them.

In the developing countries, most of which were colonized in the hey-days of empire building, communication in indigenous languages has been adversely affected by the fact of their colonization. Ngugi Wa Thiong'o, a foremost crusader for the use of African languages for creative writing by Africans, underscores the great importance of language to a people's definition of reality:

Since the new language as a means of communication was a product of and was reflecting the 'real' language of life elsewhere, it could never as spoken or written properly reflect or imitate the real life of that community. This may in part explain why technology always appears to us as slightly external, their product and not ours. (1986, p. 116).

Elugbe (1991, p. 44) stressed also that: "People are just as attached to their languages as they are to other aspects of their culture, such as religion, way of dressing, a political system, and so on; it is not easy to make them give up their language."

Perhaps as a result of this, language is a major aspect of culture which every society guards jealously for, among other things, the "transmission of the cultural heritage" as submitted by Lasswell, $(1948 ; 11)$ Language is used not only in interpersonal communication, but also in the transmission of mass mediated messages. Technology has made possible the emergence of media of mass communication which have improved communication systems within and among communities. These media of mass communication basically fall into 
two broad categories. The first category is print, which include newspapers and magazines. The second category is the electronic media, made up of radio, television, film and the new media of internet. What is, however, of importance is that these media disseminate messages through the use of language.

Because of the colonial history of Nigeria, coupled with the diversity of its ethnic composition, English is the official language of the country and the major medium of communication. For this reason, native languages do not appear to be highly esteemed.

The situation is not different in other African countries. Ngugi (1986) attests to this fact while narrating an experience he had in school after the 1952 declaration of state of emergency in Kenya:

English became more than a language; it was the language, and all the others had to bow before it in deference. Thus, one of the most humiliating experiences was to be caught speaking Gikuyu in the vicinity of the school. The culprit was given corporal punishment - three to five strokes of the cane on bare buttocks - or was made to carry a metal plate around the neck with inscriptions such as I AM STUPID or I AM A DONKEY. Sometimes, the culprits were fined money they could hardly afford (p. 11).

The media of mass communication are also caught in this web as they disseminate information mostly in the foreign language. In this, the print media appear to be more culpable as the electronic media have done a better job of deploying in native languages. This is probably accounted for by virtue of their being principally oral and aural. As noted by Salawu (1993, p. 2), being oral, the indigenous language does not cost the broadcaster (who may not be able to write it) anything to broadcast in it. Also, being aural, it does not cost the listener who may not able to read the language anything to listen to it. In Nigeria, for instance, the print media are largely urban-oriented. Because of the nature of the production, transmission of messages and cost, they obviously are not the channels for the rural dwellers and the urban poor. Consequently, they use English and focus their attention on the urban people, some of whom can read English.

Of course there are newspapers published in some of Nigeria's native languages, but they suffer critically from a low level of awareness and patronage. Ironically, Coker (1968, p. 41) asserted that Iroyin Yoruba, established in 1945, was the most widely read weekly in the 1940s. Gradually, however, the readership base became more and more Anglicized and, therefore, and the people jettisoned the habit of reading the indigenous language newspapers. On this issue, Salawu commented that the neglect these newspapers suffered is not only from the general public; most of those who work in the establishments where the newspapers are published do not give them any consideration (1993, p. 4). For instance, advertisement executives in these establishments are not always enthusiastic about canvassing for advertisements for these media. Their lack of enthusiasm may also have been a result of the unwillingness of advertisers to put their ads in these indigenous language newspapers.

Given this situation, the managements of these newspapers establishments do not consider the indigenous language section as very important, especially when it comes to allocation of resources such as newsprint. All attention is focused on other titles of the establishments published in English. All this is traceable to the colonial heritage which discouraged the most educated Nigerians from reading and writing in their native languages.

Berlo defines language thus:

\section{Language And Communication}

A system involving both elements and structures. As in any system, we can define elemental and structural units at many levels, depending on purpose. At any level, however, language includes a set of symbols and the meaningful methods of combining those units....(1960, p. 172)

Here, language is defined in terms of elements and structures within the system. Other scholars have concentrated more or less on different aspects of the phenomenon. Block and Trapper (1942, p. 5), for instance, focus on the social function of language. According to them, language is "a system of arbitrary vocal symbols by means of which a social group co-operates". Hall (1968: 158) defines language as "the institution whereby humans communicate and interact with each other by means of habitually- used oral-auditory arbitrary symbols". Noting that no particular definition of language can be exhaustive. Fromkin, Rodman and Hyams (2007:76), stress the flexibility and adaptability of language thus: "Languages are infinitely extendable and modifiable to the changing needs and conditions of speakers". This, therefore, according to Holm(2000:61) underscores the fact that language is adaptable to new situations, new ideas, and new aspects of culture.

A number of theories have been propounded about the origin of language. From the assumptions of these theories, Berlo (1960) in Fromkin and others(2007:101) draws out some implications which are:

1. Language consists of a set of significant symbols (vocabulary) plus meaningful methods for their combination (syntax).

2. The symbols of a language were chosen by chance. They are not fixed or God-given.

3. Man constructed his own language under the same principles of interpretation, response, and reward that govern all learning. 
4. Man gradually created language in order to express his meanings to himself and others, to get other people to have the same meanings, and to make responses that increased his ability to affect.

From the above, it can be inferred that language is innate and unique to man; and that it captures man's world of reality; serves as the vehicle of man's interaction (communication) with others; and that no language is superior to others. It is evident in these theoretical constructs that language plays a significant role in the totality of culture. Hoijer (1982: 211) says language, far from being simply a technique of communication, is itself a way of directing the perceptions of its speakers and it provides for them habitual modes of analyzing experience into significant categories.

Trudgil (2001: 156) moves this thesis further when he writes that:

Language is the prerequisite for the accumulation and transmission of other cultural traits. Such fundamental aspects of culture as organized political life, legal systems, religion and science are inconceivable without that most basic and human of tools, a linguistic system of communication. Language is not only a necessary condition for culture, it is itself part of culture.

Consequently, if it is agreed to that language reflects the culture of a people, it is logical to say that people would express themselves and their cultures better in the language of their own culture. Communication is better advanced in a medium that expresses the totality of the culture of a given people. This is to say that rather than communicating in English, native speakers of Yoruba would fare better if they communicate in their mother-tongue Yoruba.

Chieka (1982:45) argues, further, the case for the use of native language in bringing about development. In his words:

Each local language has always been down the millennia, at once an integral part, a repository and a vehicle of expression and transmission of its culture. Naturally, therefore, it has hitherto been part of the development and application of that culture. In reality, nation can hardly be fully developed and applied outside native language....

\section{Development, Development Communication and Diffusion of Innovations}

Development: The concept 'development' has undergone a kaleidoscopic treatment over the decades. In the past, development had been largely viewed as economic, with the development of a nation being marked with such indices as Gross National Product (GNP), Gross Domestic Product (GDP) and Per Capital Income. The assumption was that the benefit of economic advancement, even if initially concentrated in the metropolitan centres, would eventually trickle down to the periphery. This assumption has been described as being both simplistic and unworkable (Mabogunje 1980:21; Hamelink 1983:14). The underlying point here is that national economic growth does not translate to the well-being of the citizens. Mabogunje contends that this assumption results in a situation where foreign wealth, produced with the shores of an indigent country, was falsely credited to its citizenry when, in fact, such populace continues to wallow in poverty, while international statistics parades them as growing, even developing. Meanwhile, the whole world has realized the hollowness of this and has, therefore, evolved alternative development paradigms. According to Onimode (1995:26), the indicators of these alternative paradigms are:

Human Development Index (HDI) popularized by the UNDP; its Sustainable Human Development (SHD); people-centred development through people's empowerment, popular participation and 'putting the people first'; bottom-up development from the grassroots; environmental accounting; and the restructuring of the world economic and financial system along with the UN systems and the Bretton Woods Institutions.

Since economic growth through industrialization had been faulted as the legitimate development goal, the new paradigm that emerged in the late 1960s and 1970s had shifted emphasis of development goals towards:

1. Equality of the distribution of socio-economic benefits, information, resources, wealth, among others.

2. Popular participation in self- development planning and execution, usually accompany

3. Self-reliance and independence in development, with an emphasis upon the potential of local resources, and;

4. Integration of traditional with modern systems, so that modernization is a synchronization of old and new ideas, with the exact mixture somewhat different in each locale (Rogers, 1976: 45).

Suld and Tyson (1978: 36), in specific terms, categorize development goals for the purpose of planning.

1. Physical and mental health, which also involves proper nutrition, shelter and housing, work safety, recreation and leisure and community participation.

2. Security, dignity and freedom which entail equal protection under law, equal respect and dignity, freedom of expression, communication and peaceful assembly, security against crime, among others

3. Education and training; and

4. Culture and leisure

The inference drawn from the above is that the goal of development is humanitarian and peoplecentered and the world community is already aware of its essence. For instance, the World Summit on Children in 1990, United Nations Conference on Environmental Development (UNCED) in 1992, World Conference on 
Human Rights 1993, the Year of the World's Indigenous People 1993, Sustainable Development of Small Islands 1994, International Year of the Family 1994, International Conference on Population and Development (ICPD) 1994, World Social Development Summit 1995 and UN Women's Conference 1995, have all underscored the need to put people of all categories in the centre of development. In fact, the kind of development this study is preoccupied with is one that improves the quality of lives of people and moves the society to desirable ideals. The indicators of this for the people are appropriate health programmes, increased food production, housing, higher income, environmental health, mass and adult literacy, urban and rural development, population control, youth and child development, justice, democracy, unity and enhancement of culture.

\section{Development Communication}

Moemeka (1991: 48) defines development communication as the application of the process of communication to the development process. In other words, development communication is the use of the principles and practice of exchange of ideas to fulfill development objectives. In essence, the purpose of development communication is to advance development (Quebral 1973: 29). It is further said that development requires that a mass of people with a low rate of literacy and income and the socio-economic attributes that go with it, first of all be informed about and motivated to accept and use a sizeable body of hitherto unfamiliar ideas and skills in very much less time than that process would normally take.

\section{Diffusion of Innovations}

One theory that lends direct support to the discourse is the Diffusion of Innovations. This theory deals with the spread of social change. Rogers (1962) in Trudgil(2001:113) defines diffusion as the process by which an innovation is communicated through certain channels over time among members of a social system. Diffusion is a special type of communication, concerned with the spread of messages that are laden with new ideas. Rogers says it is the newness of the idea in the message content that gives diffusion its special character as some degree of uncertainty can be reduced by an individual by obtaining information. Therefore, the "information is a difference in matter-energy that affects uncertainty in a situation where a choice exists among a set of alternatives". An innovation is an idea, practice, or object perceived as new by an individual or other unit of adoption. From the foregoing therefore, it is logical that how successfully diffused is an innovation is grossly rooted in how the massage that is being disseminated through a particular language is understood by the target audience.

\section{The Nigerian Socio-linguistic Scene}

Ajeigbe (1987:19) has noted that there are more than two thousand and five hundred languages in the world. A thousand of these are to be found on the continent of Africa and within the boundaries of Nigeria alone, two hundred and fifty (250) are found. Greenberg (1963:54) points out that all African languages derive from four basic roots. These are: Afro-Asiatic, Nilo-Saharan, Niger Korfodanian and Akoisan. Ajeigbe suggests that a quarter of all sub-Saharan languages are spoken in Nigeria. Elugbe (1991:43) contends that the celebrated differences in tribe and tongue in Nigeria are exaggerated. According to him, a genetic classification of languages of Nigeria shows that three major language families are represented in Nigeria:The Afroasiatic family; The Nilo-Saharan family and The Niger-Congo family. Describing the socio-linguistics of Nigeria further, Elugbe (1991:45) says:

Virtually all Afroasiatic languages of Nigeria are members of the Chadic branch of that family,. Such languages include Hausa, Margi, Ngizim and others. With regard to those of the Nilo-Saharan family, Yanuri is the best known of those in Nigeria and it is also the largest (the size of a language is measured in terms of the number of its speakers). But most of the languages of Nigeria (including most of the Middle Belt languages and every language below the Niger-Benue line) are to the Niger Congo family. Thus Igbo, Yoruba, Ijo(Ijaw), Kambari, Edo, Efik, Fulani, Nupe, among others, are all Niger-Congo languages.

He reveals further that Fulani are linguistically more related to the Igbo, Yoruba, Ijaw, among others, than to the Hausa. His basis is this: some linguists believe that Nilo-Saharan and Niger-Congo are related as daughters of an older kongo-Saharan super family. Therefore, Huasa, and Fulla (norally called Fulfude, the language of the Fulani) do not belong to the same family. Meanwhile, of all the numerous languages in Nigeria, twelve of them are considered major because they are spoken by a considerable percentage of Nigerians. The major languages include Edo, Efik, Fulfude, Hausa, Igala, Igbo, Ijo, Kanuri, Nupe, Tiv, Urhobo and Yoruba. Olagoke (1982:34), Salawu(1993; 2001; 2007) made a numerical distribution of some languages in Nigeria: 
The Language Factor in Nigeria's National Development: A Development Communication

Distribution of Some Nigerian Languages and their Speakers among States of the Federation

\begin{tabular}{|l|l|l|}
\hline Language & Number of speakers & States in which spoken \\
\hline Hausa & $35,000,000$ & Kaduna, Kano, Katsina, Jigawa, Kebbi Sokoto, Plateau, Bauchi \\
\hline Yoruba & $28,000,000$ & Oyo, Ogun, Ondo, Oshun, Ekiti, Lagos, Kwara, Edo, Kogi \\
\hline Igbo & $22,000,000$ & Anambra, Imo, Abia, Ebonyi, Enugu, Delta, Rivers \\
\hline Fulani & $6,000,000$ & Kebbi, Adamawa, Bauchi, Kano, Sokoto, Borno, Nasarrawa \\
\hline Kanuri & $6,000,000$ & Adamawa. Borno, Bauchi, Nasarrawa Kebbi \\
\hline Ibibio & $2,500,000$ & Akwa-Ibom \\
\hline Efik & $3,500,000$ & Cross Rivers \\
\hline Tiv & $2,000,000$ & Plateau, Benue ,Kogi \\
\hline Itsekiri & $1,500,000$ & Edo, Delta \\
\hline Ijaw & $3,250,000$ & Edo, Rivers,Bayelsa, Ondo, Delta \\
\hline Nupe & $1,000,000$ & Niger, Kwara, Kogi \\
\hline Edo & $1,000,000$ & Edo \\
\hline Urhobo & $1,000,000$ & Edo, Delta \\
\hline
\end{tabular}

As noted by Salawu(1993:56), Igbinedion(1990:149), subsumed in each of these languages in Nigeria are so many other languages. Literature in respect of language and development in Nigeria is replete with the scholarly agreement that there are at least 250 languages spoken in Nigeria. Consequently, It is obvious that Nigeria today is a multilingual society Multiplicity of languages in Nigeria leads to difficulty in communicating messages geared towards development. This is true for day-to-day communication, for broadcasting and even for passing in English language at Credit level at School Certificate Examination. To the linguist, and to some extent, to the mass communicator, the principal phenomenon that distinguishes man from other animals is his ability to communicate or speak. If one person does not understand the language of another there will be difficulty in putting their ideas across. According to Hertzler, (1965:248), "the rnultilinguality among the countries of recent nationhood of peoples striving for nationhood not only separates the different regions and segments of the population but also frequently maintains dissociation".

Numerous languages in Nigeria seemingly encourage ethnocentrism, whereby the speakers of one language see themselves as support to people who do not. This leads to mutual hostility among the diverse tribes. For instance, to the Yoruba person, anybody who does not speak or understand the Yoruba language is a "kobokobo" or an ignoramus, a foreigner or a fool. The ancient Greeks called those who did not understand Greek- Barbarians; hence the word has assumed the sinister meaning throughout the world. At present, every literate Nigerian must be a bilinguist. He must speak his native language in addition to the English Language which is the official language in Nigeria. The result is that he spends more time in language learning than his counterpart in other parts of the world who uses only his mother tongue at school, at home and for all that he has to do throughout his life time. The consequence is that the average Nigerian neither knows how to speak his mother tongue properly nor the English language. The way many Nigerians pronounce English words seems sometimes atrocious. As of now, the literate Nigerian from tribe ' $A$ ' apparently faces challenge in communicating with his illiterate counterpart from tribe ' $\mathrm{B}$ ' because they have no common frame of reference linguistically. The problem is even worse with two uneducated men from two different tribes. This ugly situation retards the development of the non-literate population who constitutes the majority in this country and hold down their upward movement in the political and socio-economic ladder.

A national language will give this country a national identity. One of the problems of Nigeria today is that of tribalism and tribalism is the direct consequence of multilingualism. Furthermore, multilingualism is a feature of under-developed economies. The more developed a country is technologically, politically and in other ways, the less the number of languages it is likely to accommodate. A comparison between the number of languages spoken in developed economies and the under-developed ones will reveal this fact.

\begin{tabular}{|c|c|c|c|}
\hline \multicolumn{2}{|c|}{$\begin{array}{l}\text { Developed Countries: } \\
\text { Per capital income more than } \$ 1,200\end{array}$} & \multicolumn{2}{|c|}{$\begin{array}{l}\text { Under developed countries per capital income } \\
\text { less than } \$ 125\end{array}$} \\
\hline Canada & 2 & Nigeria & 250 \\
\hline France & 1 & & \\
\hline Britain & 1 & Ghana & 56 \\
\hline Russia & 1 & India & 70 \\
\hline Switzerland & & & \\
\hline The Netherlands & 1 & Ethiopia & 70 \\
\hline Norway & 1 & & \\
\hline Sweden & 1 & Congo & 75 \\
\hline China & 1 & & \\
\hline Italy & 1 & & \\
\hline Portugal & 1 & Togo & 44 \\
\hline West Germany & 1 & & \\
\hline East Germany & 1 & Zambia & 40 \\
\hline Czechoslovakia & 2 & & \\
\hline Belgium & 2 & The Philippines & 70 \\
\hline Denmark & 1 & & \\
\hline The United States & 1 & & \\
\hline Japan & 1 & & \\
\hline Austria & 1 & Zaire & 200 \\
\hline
\end{tabular}




\section{(Source: Microsoft Encarta 2011)}

The point being made here is not that an immediate adoption of only one or two languages by a nation will automatically make it rich, but it appears as if a nation on the road to wealth must of necessity shun multilingualism. All the countries with high per capital income have just one or two languages spoken in their territories. On the contrary, the underdeveloped countries have up to 40 languages as is the case Zambia; 250 in Nigeria. Of what use to the nation are the 250 languages that exist in Nigeria today? Absolutely none! Rather, they increase tribal nationalism to the detriment of the nation as a whole. The crux of the matter is that any message that is directed at bringing about positive change and largely development, but is not understood by every target audience is a mere semantic noise. If this is so, since the ruralites, slumites, down trodden and the illiterate segment constitutes the integral part of Nigeria's population, the failure of a number of developmental campaigns in Nigeria can be said to be rooted in lack of awareness and understanding of the messages of the campaigns by this audience.

\section{Language Experiments In Other Parts Of The World}

It is ironical that at a time when Europe and America are trying to communicate in one language, Nigeria still appears grouping and digging every nook and cranny to "discover as many languages as it cannot cope with for its day-to-day communication. There is no doubt that the examples and achievements in other parts of the world will set the nation thinking along a more liberal and more progressive line and so take a hard look at the multiplicity of languages in the country. In the world today, there are in existence only thirteen languages each having more than 100 million speakers. They are in numerical order of magnitude; Chinese, English, German. Japanese, Arabic, Bengali, speakers which include non-natives as well as speakers. are as follows:

Chinese

English $1,000,000,000$

Hindustani

Russian $850,000,000$

Spanish

German

$350,000,000$

$280,000,000$

Japanese

$200,000,000$

Arabic,

$180,000,000$

Bengali

Portuguese

$170,000,000$

Malaya (Indonesia)

French

$165,000,000$

$150,000,000$

$150,000,000$

Italian

$150,000,000$

(Source: Microsoft Encarta 2011)

It is unfortunate that there is no African language on this chart. In spite of the numerical strength of people who speak their languages, many European nations are already planning to have world language. For instance, Esperanto is spoken to some extent in virtually all the highly and considerably developed countries like: Brazil, Bulgaria, Czechoslovakia, Hungary, Japan, Sweden, France, Germany, Greece, Britain, the United States, the Netherland, Poland and Yugoslavia. This appears laudable as the prospect for the formation of a world language is forever increasing. This will get further boost as international cooperation, trade and tourism increase.

\section{The Language For Development Communication In Nigeria}

The language for Nigeria that is being proposed is one that should be developed on a long-term basis, perhaps on a moderately-long basis. The present generation of Nigerians may not benefit from it; in fact, they may have to suffer some deprivations in order that their off springs may live harmoniously among themselves and with other races of the world. This discourse does not attempt to denigrate the study of language, but it is a position of this paper that, to study these languages and impose one on the other is seemingly anachronistic to development. The following options are hereby proposed:

\section{1) Adopt Pidgin English}

It is being suggested that pidgin English should be adopted as a national language to the exclusion of all other. The argument is that it has the elements of popularity and neutrality. But the problem with pidgin is that it is regarded with scorn throughout the world because of its crude elementary processes and because of its simplicity. It is common to find in some pidgin languages of the world six words in a sentence each taken from different languages. Moreover, there should be a near general agreement that Pidgin English of the Hausa man is different from that of the Igbo, Edo, Yoruba or Ishan person. 


\section{2) Allow A National Language To Develop Unconsciously}

One other suggestion is that a national' language should be allowed to develop unconsciously from all languages prevalent in the country. This holds that no conscious attempt should be made at uniformity. This proposal is plagued, because, language, being a repository of culture dies hard. It cannot therefore be expected to develop unconsciously. Positive attempts have to be made at uniformity. The language condition in Nigeria today is that almost every Nigerian puts forward his language for every other Nigerian to speak. Therefore, this conscious effort to search every nook and cranny for languages will never make for an unconscious emergence of a national language.

\section{3) Adopt The Three Major Languages}

The compromise position is that Nigeria should adopt the three major languages in the country, namely: Hausa, Igbo and Yoruba. In short, this is the official position as typified by the 6-3-3-4 system of education where every child is expected to study the three major languages. The problem here is that will be need to re print every book, transmit every radio and television programme in the three languages and perhaps also in English if Nigeria is to be understood by people the international community. This proposal is therefore unsatisfactory for a variety of other reasons. For instance, Nigeria may want linguistic unity in future and the problem of choice will crop up again and the argument will be counterproductive. Another problem here is that every Nigerian will have to be a "tri-linguist" in order to travel from one part of the country to another. $\mathrm{He}$ should also perhaps be required to speak the English language which makes them four. Although, there are countries like Canada (two languages) and Switzerland (four languages) which have this type of language setup, but their problem is considerably reduced because their languages are two world major languages - English and French. This suggestion will not improve issues.

\section{4) Adopt One Of The Indigenous Languages}

The next proposal is that Nigeria should adopt one of the indigenous languages currently spoken in the country as its lingua franca - say the Igbo, Hausa, Yoruba, Efik, Kanuri among others. The argument here is that a decision along this line will give the country a national identity that distinguishes it from other nations of the world. Should not Africa's most populous nation have its own language? In order to allay the fears of domination, it is further suggested that the language does not have to be one of the dominant ones in the country. For instance, Swahili is not the language of any of the big tribes in East Africa. It must be mentioned that the greatest obstacle this proposal faces is that of choosing the language itself because of sentiments that are rooted in tribalism.

\section{5) Adopt The English Language}

The final proposal is that the English .should be adopted as language for communication to the exclusion of all other. This thesis holds that many of the nation's day-to-day activities already point to the fact that the English language will forever be the language of activities both for interpersonal and mass communication. The rising rate of literacy will eventually make the use of vernacular unnecessary in the future. The proponents of this view point to the difficulty and cost to be met in translating all the books in the libraries into another language. They also point out that a world language would be a possibility in future and that the English language is the safest guard against global linguistic fluctuations. The critics of this view draw attention to the fact that language is a principal motor by which culture is transmitted and vice-versa. As one critic puts it, "The emotional importance of a language lies in the fact that it contains certain of the voices of one's mother, father, brothers and one's dearest friends, our deepest emotions and most intimate memories are tightly bound with our native tongue".

Considering the socio-linguistic situation in Nigeria, it is very difficult for an indigenous language to emerge as the national language. Because of the nation's linguistic diversity, Elugbe (1991:50) says "the choice of any of the major indigenous languages would arouse discontent in other areas not covered by that language". As a result, English, since 1947, had been adopted as the official language. This was officially stated in the popular Richard's constitution. Earlier, in 1942, Arthur Richard had given his reasons for making English the official language. According to him, the main problem was "how best to promote unity in Nigeria" because of the "patent diversity of outlook between the different parts of Nigeria". On the choice of English as Nigeria's official language, Bamgbose, quoted in Ajeigbe (1987:74) says:

Of the entire heritage left behind by Britain at the end of the colonial administration, probably none is more important than the English language. This is now the language of the government, business and commerce, education, the mass media, literature and much internal as well as external communication.

Yet, the search for a mono-national language continues. Such a search has led to attempts such as WAZOBIA, formed from WA, ZO and BIA ('come' in Yoruba, Hausa and Igbo respectively). Elugbe (1991:50) comments that WAZOBIA attempt which was short-lived "represents the possibility of evolving a national 
language that would be made up of elements of different Nigerian languages" Noting that the case for English is strong, Elugbe (1991:50), however, points that "within proper handling, one of the (major) national languagesHausa, Igbo, Yoruba- may emerge in the next few centuries as our national language".

\section{Recommendations And Conclusion}

It is believed that much of what have been said in this paper points to the fact that the English language should continue to be the language for communication and business in Nigeria. For one thing, the original owners of the language are not asking for interest like the International Monetary-Fund. English has the second largest number of speakers in the world next of Chinese. It also has the greatest geographical spread around the globe than any language. Technological inventions in the area of mass communication are a great obstacle to adopting any of the nation's indigenous languages. If another language is adopted instead of English, the cost of translating all the books in the libraries into that language will be so colossal. Also, the cost of sustaining such a language be it Hausa, Igbo or Yoruba will be so much that the effort will be a pyrrhic victory. For instance, in making computers, special one would have to be made for Nigeria to accommodate the peculiarities of the language. Finally, distinguished Nigerians like Noble Laureate, Professor Wole Soyika, and others like Professor Chinua Achebe, Ola Rotimi, have demonstrated that there is no limit to what any Nigerian can achieve using the English language as a medium of communication in Nigeria. There is no substitute to the use of English language as a medium of development communication in Nigeria.

\section{References}

[1] Berger, R. C. and Chafee, H. S. (1987). "Functions of Communication: An Introduction" in Handbook of Communication Science. Newsbury park: SAGE Publications.

[2] Berlo, D. K. (1960). The Process of Communication. San Fransisco: Rinehart Press.

[3] Chieka I. (1982). 'The Place of Local Languages in Nigeria today' in Bashir Ikara (ed) Nigeria Languages and Cultural Development. Lagos: The National Languages Centre, Federal Ministry of Education

[4] Fromkin,V.,, Rodman, R and Hyams, N.(2007) An Introduction to Language U.S.A.: Thomson Wadsworth

[5] Greenberg, J. H. (1971). The Languages of Africa. The Hague: Mouton.

[6] Hertzler, J. O., (1965) A Sociology of Language. New York: Random House,

[7] Holm, J. (2000) An Introduction to Pidgins and Creoles, Cambridge UK: Cambridge University Press

[8] Moemeka, A. A. (1990). 'The mass media, communication and rural dwellers: toward the effectiveness of development messages' in Oso. L. and Adebayo, L. (eds) Communication and rural development in Nigeria. Abeokuta: Millenium Investments Ltd.

[9] Moemeka, A. (1991). 'Perspective on Development Communication' in K. Boafo (ed) Module on Development Communication. (1) Nairobi: ACCE

[10] Ngugi, W. T. (1986). Decolonizing the Mind: The Politics of Languages in African Literature. London: James Currey.

[11] Trudgill, P. (2001), Sociolinguistics, An Introduction to Language and Society $4^{\text {th }}$ edition London: Penguin Books

[12] Salawu, A. S. (1993). 'A study of selected vernacular newspapers in Nigeria'. Unpublished M. Sc. Thesis, University of Lagos 